\title{
Poly(ADP-ribose) polymerase-1 (PARP1) and p53 labelling index correlates with tumour grade in meningiomas
}

\author{
Tamás Csonka ${ }^{1}$, Balázs Murnyák ${ }^{1}$, Rita Szepesi² ${ }^{2}$ Andrea Kurucz ${ }^{1}$, Álmos Klekner ${ }^{3}$, Tibor Hortobágyi ${ }^{1}$ \\ ${ }^{1}$ Division of Neuropathology, Institute of Pathology, ${ }^{2}$ Department of Neurology, ${ }^{3}$ Department of Neurosurgery, Faculty of Medicine, \\ University of Debrecen, Debrecen, Hungary
}

\begin{abstract}
Meningiomas are one of the most frequent intracranial tumours, with 13 histological types and three grades according to the 2007 WHO Classification of Tumours of the Central Nervous System. p53, as one of the most potent tumour suppressor proteins, plays a role in nearly 50\% of human tumours. Poly(ADP-ribose) polymerase (PARP) is a DNA repair enzyme with high ATP demand. It plays a role in apoptosis by activating an apoptosis inducing factor, and in necrosis by consuming NAD+ and ATP. Only PARP1 has been investigated in detail in tumours out of the 17 members of the PARP superfamily; however, its role has not been studied in meningiomas yet. The aim of this study was to determine the role of $p 53$ and PARP 1 in meningiomas of different grade and to establish whether there is any correlation between the $p 53$ and PARP1 expression. Both PARP1 and $p 53$ have been expressed in all examined meningiomas. PARP1 labelled grade II tumours with a higher intensity as compared to grade I and III neoplasms, respectively. An increased $p 53$ expression was noted in grade III meningiomas. There was no statistical correlation between $p 53$ and PARP1 expression. Our data indicate that both PARP1 and $p 53$ activation is a feature in meningiomas of higher grade, PARP1 overexpression being an early, whereas $p 53$ overexpression, a late event in tumour progression.
\end{abstract}

Key words: meningioma, poly(ADP-ribose) polymerase (PARP), p53.

\section{Introduction}

Meningiomas are frequent primary brain tumours representing approximately $30 \%$ of all primary intracranial tumours. The incidence is increasing with age and has a slight female predominance [32,59]. The aetiology is not entirely understood, but the increased risk after whole brain radiation therapy is well known [38]. There are several subtypes, like meningothelial, fibrous, transitional, psammomatous, angiomatous, microcystic, secretory, lympho- plasmacyte-rich, sometimes with crystalline inclusions [5], metaplastic, choroid, clear cell, rhabdoid, papillary and other rare or miscellaneous types [34]. According to the ultrastructural findings, some of the intranuclear vacuoles are produced during autophagy [18]. The heterogeneous glycosylation pattern has also been demonstrated in different subtypes of meningiomas, and it indicates the usefulness of lectins in the evaluation of pluripotential differentiation 
of meningioma cells [56]. The current prediction of clinical behaviour is based on the morphological findings, brain invasion, mitosis index and Mib1 immunostaining $[1,47,48]$. Meningiomas show positive immunoreactivity for epithelial membrane antigen, oestrogen and progesterone receptors [45]; however these immunohistochemical markers do not help with the determination of the grade. CD31 immunostaining is good for revealing the blood vessel number that is higher in atypical meningiomas than WHO grade I tumours [31], but this marker is not used in routine diagnostic work-up. Despite these findings, there is a need for more "malignant" markers for meningiomas that can be used in routine diagnostic work and a group of them could be the DNA repair genes like $p 53$ or poly(ADP-ribose) polymerase (PARP) in the future.

PARP protein superfamily has 17 members. All of them have four domains: catalytic, auto-modification, caspase-cleaved and DNA-binding domain. Some of them have PARP activity, as PARP1 or PARP2 and some of them do not, as PARP3 or PARP6.

PARP1 is a $113 \mathrm{kDa}$ protein, located in the nucleus. The gene of PARP1 is located on the long arm of chromosome 1 (1q42.12). The cDNA was isolated and sequenced first by Kurosaki et al. [26]. One of the main functions of PARP1 is its role in the repair of single-stranded DNA breaks (SSB). After detecting the SSB damage by chemical, radiation or metabolic induction, the enzyme is activated and binds to the DNA, undergoes a structural transformation before it produces poly(ADP-ribose) (PAR) chain by a nicotinamide adenine dinucleotide (NAD+), consuming the process. PAR is a signal for other repair genes during base excision repair (BER) $[9,29,35]$. Activated PARP1 can poly(ADP-ribosyl)ate (PARylate) nuclear enzymes thereby increasing the negative charge and preventing the interaction with other anionic molecules including the DNA. Among the DNA repair functions, activated PARP1 has a vital role in apoptosis by translocation of the apoptosis inducing factor (AIF) from the mitochondria to the nucleus $[60,61]$. However, if there is a high level of DNA damage, necrotic cell death is triggered by activating a large number of PARP1, consuming NAD+ and the ensuing ATP depletion [3]. The role of PARP1 activation cascade has also been demonstrated in neuronal stem cell transplantation after brain injury in rats [27], as well as PARP1 is also activated in the ischemia-reperfusion injury [55], and the early activation of PARP1 after cold lesion that is - at least in part - related to neuronal NO synthetase (nNOS) induction [16]. The role of PARP1 has been revealed in the regulation of glycogen synthase kinase-3 (GSK3) that is responsible for the hyperphosphorylation of tau [54], and the amyloid peptide affected signal transduction to PARP1 in Alzheimer's disease [2].

It has been demonstrated that PARP1 has a role in the BRCA1/BRCA2 mutated breast carcinomas because PARP1 inhibitors can trigger the effectiveness of the chemotherapeutic agents by inhibiting the SSB-repair, when the double-stranded DNA repair is also diminished by the BRCA mutation [11]. The role of PARP1 has been described in other tumours such as breast [51], ovarian [6], pancreatic carcinomas [24], gastric carcinomas [62], prostate carcinomas [53], melanomas [13,40] and glioblastomas [12,21] but has not been investigated in meningiomas yet.

p53 is one of the most significant tumour suppressor proteins, encoded by the TP53 gene on the short arm of chromosome 17 (17p13.1) [17,33]. The physiological functions of $\mathrm{p} 53$ are cell cycle regulation and conservation of the stability of the genome by preventing mutations. The 393 amino acid long, 43.7 $\mathrm{kDa}$ weight protein has 7 domains, such as two activation domains (AD1 and AD2), a proline-rich domain, a DNA-binding core domain (DBD), a signalling domain, a homo-oligomerisation domain (OD) and a C-terminal downregulation domain. p53 can be activated by DNA damage, oxidative stress, osmotic shock, ribonucleotide depletion or oncogene expression. The activation is marked by an increase in the half-life of p53 and a change of its conformation [22]. Mdm2 is responsible for the low level of p53 in an unstressed cell, by binding to p53 and preventing its action, and it also transports p53 to the cytosol, and attaches ubiquitin to it covalently.

The anticancer activity of $p 53$ works through several mechanisms: it activates DNA repair proteins, induces growth arrest at the G1/S regulation point through p21 [10] or initiates apoptosis if the DNA damage is irreversible. Mutagens can damage TP53 causing unregulated cell proliferation; more than 50 percent of human tumours contain a deletion or mutation of the TP53 gene [15]. p53 was voted the molecule of the year in 1993 by the Science magazine [25], due to its key roles.

The role of $\mathrm{p} 53$ has already been examined in the meningiomas: some of the examinations ended with negative or equivocal findings [43,48-50], but some 
of them showed a significant correlation between the p53 status and the grade or recurrence of the tumour $[4,7,8,19,20,28,37,41,44,46,57]$. It is also described that p53 immunopositive cells are more frequent in the perinecrotic areas of post-embolised cases than in preserved parts of the tumour [39].

Several theses have been written about the interaction between the PARP1 and the p53. Wieler et al. showed that the inhibition of endogenous PARP1 functions suppresses the transactivation function of p53 in response to ionizing radiation; hence PARP1 is a key regulator of the $p 53$ response to DNA damage [58]. Malanga et al. showed that ADP-ribose polymers play a role in regulating the DNA binding properties of $p 53$ by preventing and reversing $p 53$ binding to the palindromic p53 consensus sequence [36]. Lee et al. has recently discovered a novel role for PARylation of p53 in the gene-specific regulation of the transcriptional mode of p53 on the promoter of MTA1 [30]. Godoy et al. revealed overexpression of PARP1 and p53 in high-grade and advanced stage tumours in epithelial ovarian cancer, and it indicated that these 2 markers might serve as a marker of aggressive disease behaviour [14]. Sabisz et al. showed the crucial part of PARP1 activity in the maintenance of the $\mathrm{G} 2$ arrest induced by DNA damaging drugs; thus, inhibitors of PARP1 may be used as non-genotoxic agents to activate p53 in cancer cells with non-functional p53 pathways [52]. PARylation of transcription factors such as p53, NFkB, and Sp1 prevents their binding to DNA and formation of transcription complexes [42].

The aim of this study is to find any correlation between the PARP1 and p53 immunostaining and the WHO grade of the tumours, and between the PARP1 and p53 immunopositivity.

\section{Material and methods}

The histological slides of 31 meningioma patients have been studied. Patients have been divided into three groups according to the WHO Classification of Tumours of the Central Nervous System [34]. After the surgical removal, sections were created and stained for haematoxylin-eosin (H\&E) from formalin-fixed and paraffin-embedded (FFPE) blocks for a routine diagnostic procedure in the Institute of $\mathrm{Pa}$ thology. All of the cases have been revised by a consultant neuropathologist (TH).
Immunohistochemistry (IHC) has been performed according to standardized methods as described in detail, in earlier publications [16,17]. In brief, $4 \mu \mathrm{m}$ thick sections from FFPE blocks have been stained for PARP1 rabbit polyclonal antibody (ab6079) (Abcam Plc., Cambridge, England) and p53 DO-7 mouse monoclonal antibody (M7001) (DAKO, Denmark) according to the manufacturer's protocol. Using a $1: 500$ and 1 : 700 dilution for PARP1 and p53, respectively, with Novocastra Bond ${ }^{\mathrm{TM}}$ Polymer Refine Detection kit on Leica Bond Max ${ }^{\mathrm{TM}}$ fully automated IHC stainer, with negative controls (Fig. 1).

100 cells in 10 fields of vision on 40x magnification have been examined; the staining intensity has been evaluated as none (0), weak (1+), moderate (2+) and strong (3+) from all of the slides for both PARP1 and p53 (Fig. 2). We have created two parameters in all cases regarding to the staining intensity $(\mathrm{Si})$ ratio of the $1+, 2+$ and $3+$ cells Si1-3, and ratio of the 2+ and $3+$ cells Si2-3, similarly as HER2 immunohistochemistry evaluation in breast carcinomas (Table I).

The results have been analysed by SPSS 19.0 for Windows statistical software. After comparing with Kruskal-Wallis $\mathrm{H}$ test the Si1-3 and Si2-3, performing Mann-Whitney $U$ test on all of the grade pairs for both PARP1 and p53. Next, we have created two groups - low grade (WHO grade I) and high grade (WHO grade II and WHO grade III) [23] and have compared them by Mann-Whitney $U$ test. We also have performed Spearman's rank order correlation analysis to determine whether there is any correlation between the PARP1 and p53 immunopositivity.

Ethical approval has been sought from the Institutional Research Ethics Committee.

\section{Results}

Both PARP1 and p53 have been expressed in all of the 41 cases.

There was a significant correlation between tumour grade and presence of PARP1 expression (staining intensity $(\mathrm{Si}) 1-3)(p=0.001)$ and presence of explicit positivity (Si2-3) for p53 ( $p=0.012)$, respectively, with Kruskal-Wallis $\mathrm{H}$ test. In contrast, there was no statistically significant association between grade and Si2-3 for PARP1, Si1-3 for p53, $p=0.523$ and $p=0.141$, respectively.

As next, we have compared different grades and performed Mann-Whitney $U$ test. The Si1-3 for PARP1 between grade I and grade II, as well as grade II and 

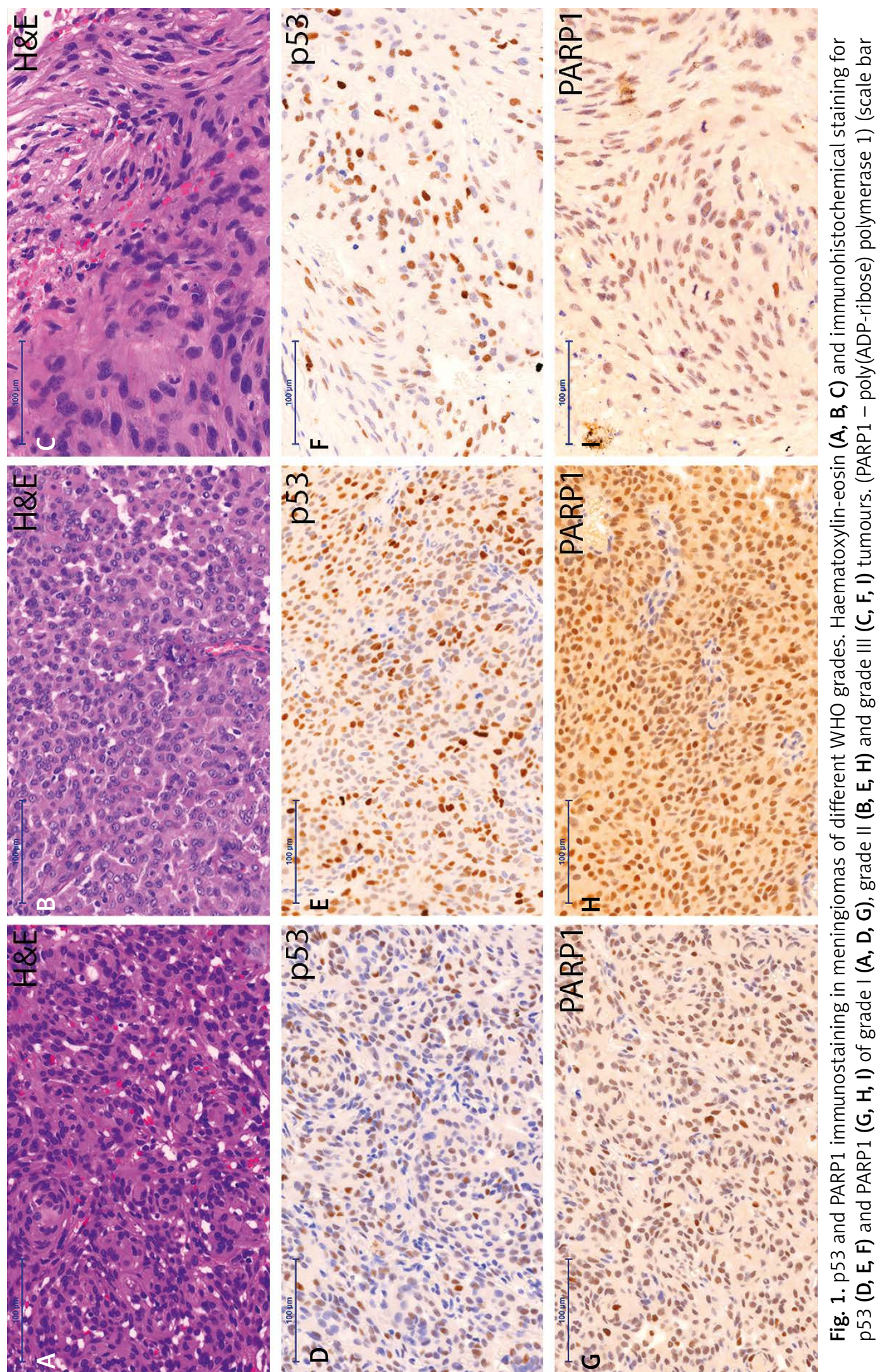

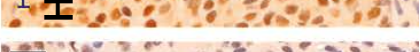

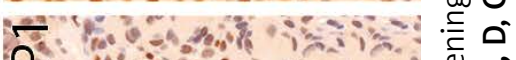
त 0.00

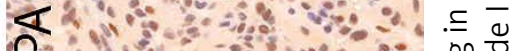

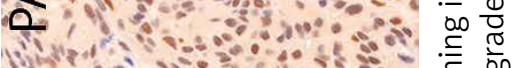

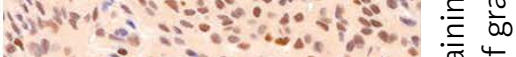

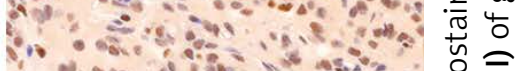

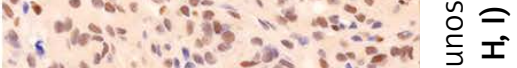

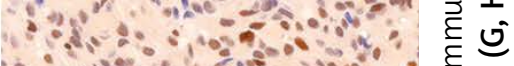
A a diger

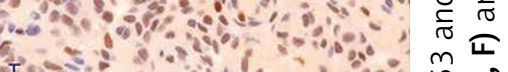
Ho

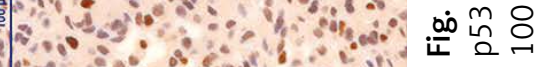

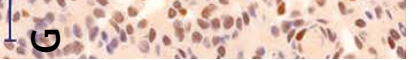


grade III (Fig. 3A); and the Si2-3 for p53 between grade I and grade III (Fig. 3B) significantly correlated with the WHO grades $(p=0.001$ and $p=0.005$, $p=0.002$, respectively). Grade II tumours showed the highest mean index of the PARP1 staining (Fig. 3A), while grade III tumours had the highest staining index for p53 (Fig. 3B).

The Mann-Whitney $U$ test, performed on the lowgrade and high-grade groups, showed a significant correlation between Si1-3 for PARP1 (Fig. 3C) and Si2-3 for p53 (Fig. 3D), $p=0.028$ and $p=0.018$, respectively.

Among grade I tumours there were 11 meningothelial, 8 transitional, 1 secretory, 1 fibrous and 1 microcystic; among grade II tumours -8 atypical and 3 clear cell; all the grade III tumours were anaplastic (i.e. not papillary and rhabdoid). There was no significant difference between the staining intensity of PARP and p53 between subtypes of any grades; however, the case numbers were rather low to make statistically valid comparisons.

There was no significant correlation between PARP1 and p53 with Spearman's rank order correlation analysis (Fig. 4).

\section{Discussion}

Meningiomas are one of the most frequent intracranial tumours with diverse morphological variants. The current WHO classification [34] distinguishes 13 histological types. Nine of them belong to grade I; 2 and 2 belong to grade II and grade III, respectively. There are morphological criteria that define atypical (WHO grade II) and anaplastic (WHO grade III) meningiomas; however, the distinction is often difficult. Until now there has been no highly trusted immunohistochemical marker that can separate the different WHO grades reliably.

PARP1 protein role has been demonstrated in the repair of the damaged DNA, however this protein also has an important role in the caspase independent apoptotic pathway and in necrotic cell death. p53 is one of the most important tumour suppressor proteins, it has a role in almost half of the human tumours. Several studies have been performed about the p53 marker, but those ended with equivocal results. PARP1 protein expression in meningiomas has not been examined yet.

In this study, all of the 41 cases showed immunopositivity for both PARP1 and p53. The proportion
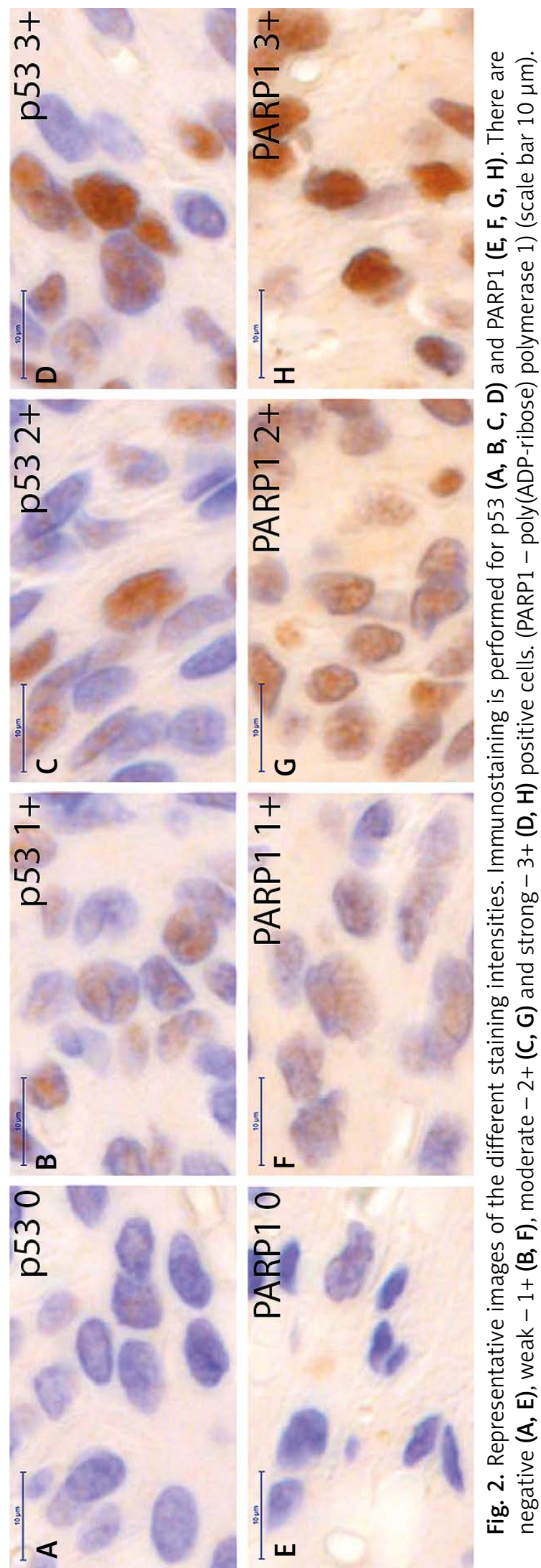
Table I. Data sheet on cell counts showing staining intensities and their respective proportion to all counted cells. Staining index (Si) $1-3$ is the ratio of the immunopositive $(1+, 2+, 3+)$ cells; and the Si2-3 is the ratio of the intense positive $(2+, 3+)$ cells. (PARP1 - poly(ADP-ribose) polymerase 1 )

\begin{tabular}{|c|c|c|c|c|c|c|c|c|c|c|c|c|c|c|c|}
\hline \multirow{2}{*}{$\begin{array}{c}\text { Patient } \\
\text { No. }\end{array}$} & \multirow{2}{*}{$\begin{array}{c}\text { Slide } \\
\text { No. }\end{array}$} & \multirow{2}{*}{$\begin{array}{l}\text { WHO } \\
\text { Grade }\end{array}$} & \multirow{2}{*}{ Subtype } & \multicolumn{6}{|c|}{ PARP1 } & \multicolumn{6}{|c|}{ p53 } \\
\hline & & & & 0 & $1+$ & $2+$ & $3+$ & Si1-3 & $\mathrm{Si} 2-3$ & 0 & $1+$ & $2+$ & $3+$ & Si1-3 & $\mathrm{Si} 2-3$ \\
\hline 1 & 1 & I & Meningothelial & 5 & 85 & 9 & 1 & 0.95 & 0.1 & 49 & 34 & 14 & 3 & 0.51 & 0.17 \\
\hline 2 & 2 & I & Meningothelial & 16 & 39 & 37 & 8 & 0.84 & 0.45 & 49 & 43 & 8 & 0 & 0.51 & 0.08 \\
\hline 3 & 3 & I & Meningothelial & 22 & 74 & 4 & 0 & 0.78 & 0.04 & 70 & 27 & 3 & 0 & 0.3 & 0.03 \\
\hline 4 & 4 & I & Transitional & 10 & 65 & 25 & 0 & 0.9 & 0.25 & 46 & 50 & 4 & 0 & 0.54 & 0.04 \\
\hline 5 & 5 & I & Meningothelial & 26 & 50 & 13 & 11 & 0.74 & 0.24 & 57 & 39 & 4 & 0 & 0.43 & 0.04 \\
\hline 6 & 6 & I & Meningothelial & 8 & 83 & 9 & 0 & 0.92 & 0.09 & 76 & 24 & 0 & 0 & 0.24 & 0 \\
\hline 7 & 7 & I & Transitional & 32 & 66 & 2 & 0 & 0.68 & 0.02 & 75 & 24 & 1 & 0 & 0.25 & 0.01 \\
\hline 8 & 8 & 1 & Meningothelial & 15 & 83 & 2 & 0 & 0.85 & 0.02 & 52 & 34 & 14 & 0 & 0.48 & 0.14 \\
\hline 9 & 9 & I & Secretory & 22 & 75 & 3 & 0 & 0.78 & 0.03 & 75 & 17 & 7 & 1 & 0.25 & 0.08 \\
\hline 10 & 10 & I & Meningothelial & 23 & 37 & 38 & 2 & 0.77 & 0.4 & 71 & 23 & 6 & 0 & 0.29 & 0.06 \\
\hline 11 & 11 & I & Fibrous & 21 & 30 & 24 & 25 & 0.79 & 0.49 & 47 & 50 & 3 & 0 & 0.53 & 0.03 \\
\hline 12 & 12 & I & Transitional & 15 & 66 & 19 & 0 & 0.85 & 0.19 & 53 & 38 & 9 & 0 & 0.47 & 0.09 \\
\hline 13 & 13 & I & Meningothelial & 7 & 93 & 0 & 0 & 0.93 & 0 & 86 & 12 & 2 & 0 & 0.14 & 0.02 \\
\hline 14 & 14 & I & Meningothelial & 11 & 68 & 20 & 1 & 0.89 & 0.21 & 76 & 23 & 1 & 0 & 0.24 & 0.01 \\
\hline 15 & 15 & I & Microcystic & 5 & 36 & 59 & 0 & 0.95 & 0.59 & 83 & 17 & 0 & 0 & 0.17 & 0 \\
\hline 16 & 16 & 1 & Transitional & 10 & 85 & 4 & 1 & 0.9 & 0.05 & 52 & 43 & 5 & 0 & 0.48 & 0.05 \\
\hline 17 & 17 & I & Transitional & 6 & 89 & 5 & 0 & 0.94 & 0.05 & 73 & 21 & 6 & 0 & 0.27 & 0.06 \\
\hline 18 & 18 & I & Transitional & 16 & 33 & 48 & 3 & 0.84 & 0.51 & 79 & 18 & 3 & 0 & 0.21 & 0.03 \\
\hline 19 & 19 & II & Atypical & 10 & 77 & 11 & 2 & 0.9 & 0.13 & 60 & 30 & 10 & 0 & 0.4 & 0.1 \\
\hline 20 & 20 & II & Atypical & 8 & 64 & 26 & 2 & 0.92 & 0.28 & 76 & 24 & 0 & 0 & 0.24 & 0 \\
\hline 21 & 21 & II & Atypical & 1 & 67 & 32 & 0 & 0.99 & 0.32 & 85 & 13 & 2 & 0 & 0.15 & 0.02 \\
\hline 22 & 22 & II & Clear cell & 2 & 80 & 18 & 0 & 0.98 & 0.18 & 68 & 29 & 3 & 0 & 0.32 & 0.03 \\
\hline 23 & 23 & II & Atypical & 14 & 71 & 10 & 5 & 0.86 & 0.15 & 78 & 18 & 4 & 0 & 0.22 & 0.04 \\
\hline 23 & 24 & 1 & Transitional & 9 & 72 & 16 & 3 & 0.91 & 0.19 & 69 & 31 & 0 & 0 & 0.31 & 0 \\
\hline 24 & 25 & II & Atypical & 6 & 71 & 21 & 2 & 0.94 & 0.23 & 80 & 18 & 2 & 0 & 0.2 & 0.02 \\
\hline 25 & 26 & II & Atypical & 1 & 84 & 15 & 0 & 0.99 & 0.15 & 72 & 23 & 5 & 0 & 0.28 & 0.05 \\
\hline 25 & 27 & II & Clear cell & 1 & 44 & 53 & 2 & 0.99 & 0.55 & 44 & 39 & 15 & 2 & 0.56 & 0.17 \\
\hline 25 & 28 & II & Clear cell & 0 & 27 & 49 & 24 & 1 & 0.73 & 38 & 32 & 27 & 3 & 0.62 & 0.3 \\
\hline 25 & 29 & I & Meningothelial & 10 & 81 & 9 & 0 & 0.9 & 0.09 & 67 & 29 & 4 & 0 & 0.33 & 0.04 \\
\hline 25 & 30 & I & Meningothelial & 4 & 77 & 16 & 3 & 0.96 & 0.19 & 71 & 21 & 6 & 2 & 0.29 & 0.08 \\
\hline 25 & 31 & I & Transitional & 9 & 82 & 9 & 0 & 0.91 & 0.09 & 67 & 27 & 6 & 0 & 0.33 & 0.06 \\
\hline 26 & 32 & II & Atypical & 0 & 33 & 63 & 4 & 1 & 0.67 & 35 & 39 & 26 & 0 & 0.65 & 0.26 \\
\hline 27 & 35 & III & Anaplastic & 10 & 81 & 9 & 0 & 0.9 & 0.09 & 59 & 29 & 10 & 2 & 0.41 & 0.12 \\
\hline 27 & 34 & III & Anaplastic & 8 & 42 & 40 & 10 & 0.92 & 0.5 & 30 & 47 & 22 & 1 & 0.7 & 0.23 \\
\hline 27 & 33 & II & Atypical & 4 & 83 & 10 & 3 & 0.96 & 0.13 & 71 & 21 & 7 & 1 & 0.29 & 0.08 \\
\hline 28 & 36 & III & Anaplastic & 10 & 74 & 15 & 1 & 0.9 & 0.16 & 42 & 28 & 17 & 13 & 0.58 & 0.3 \\
\hline 28 & 37 & III & Anaplastic & 20 & 66 & 14 & 0 & 0.8 & 0.14 & 49 & 20 & 17 & 14 & 0.51 & 0.31 \\
\hline 28 & 38 & III & Anaplastic & 4 & 47 & 48 & 1 & 0.96 & 0.49 & 79 & 19 & 2 & 0 & 0.21 & 0.02 \\
\hline 29 & 39 & III & Anaplastic & 14 & 71 & 14 & 1 & 0.86 & 0.15 & 68 & 22 & 7 & 3 & 0.32 & 0.1 \\
\hline 30 & 40 & III & Anaplastic & 25 & 73 & 2 & 0 & 0.75 & 0.02 & 54 & 26 & 13 & 7 & 0.46 & 0.2 \\
\hline 31 & 41 & III & Anaplastic & 28 & 62 & 10 & 0 & 0.72 & 0.1 & 76 & 15 & 9 & 0 & 0.24 & 0.09 \\
\hline
\end{tabular}



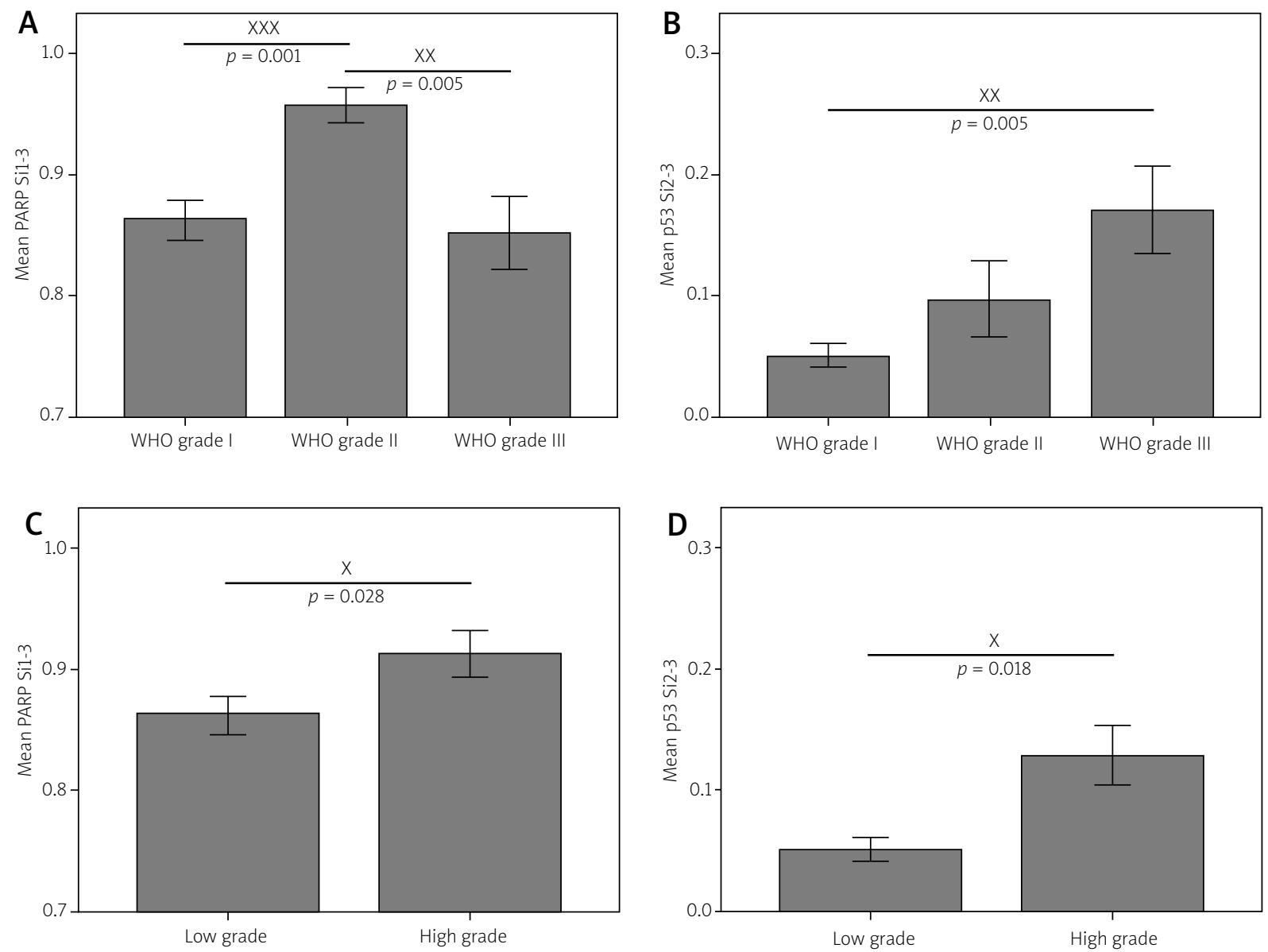

Fig. 3. $p 53$ and PARP staining intensity varies according to the tumour grade. Mean values of the staining index (Si)1-3 for PARP1 (A, C) and Si2-3 for p53 (B, D) regarding to the WHO grades (A, B), and low grade WHO grade I and high grade - WHO grade II and WHO grade III (C, D). Error bars \pm standard error of mean (SEM). $p$ values are calculated by Mann-Whitney $U$ test. (PARP1 - poly(ADP-ribose) polymerase 1; staining index (Si)1-3 is the ratio of the immunopositive $(1+, 2+, 3+)$ cells; and the Si2-3 is the ratio of the intense positive $(2+, 3+)$ cells).

of positive cells (Si1-3) was higher in grade II tumours for PARP1, as compared to grade I and grade III meningiomas, respectively. Increased immunopositivity (Si2-3) was noted in grade III tumours for p53. Comparing the immunopositive cells in the lowgrade meningiomas (grade I) and in the high-grade meningiomas (grade II and grade III) we found more immunopositive cells (Si1-3) for PARP1 and a higher staining intensity (Si2-3) for p53 in the high-grade tumours.

Performing a Spearman's rank order correlation and linear regression, there was no statistical correlation between either the presence of positivity or the intense immunoreactions for p53 and PARP1, thus the expression of these two proteins does not appear to be related to each other. We suggest that PARP1 activation increases in grade II tumours to cope with the DNA damage, whereas in grade III tumours PARP1 activity is decreased as a consequence of apoptotic-necrotic cell death and preceding overactivation and consecutive consumption of the protein and substrates.

Our data confirm that $\mathrm{p} 53$ protein plays a role in meningiomas, and indicate that the p53 activation might be a late event in the progression of meningothelial neoplasms.

Although further studies are necessary to elucidate the role of PARP1 and p53 in meningiomas, 

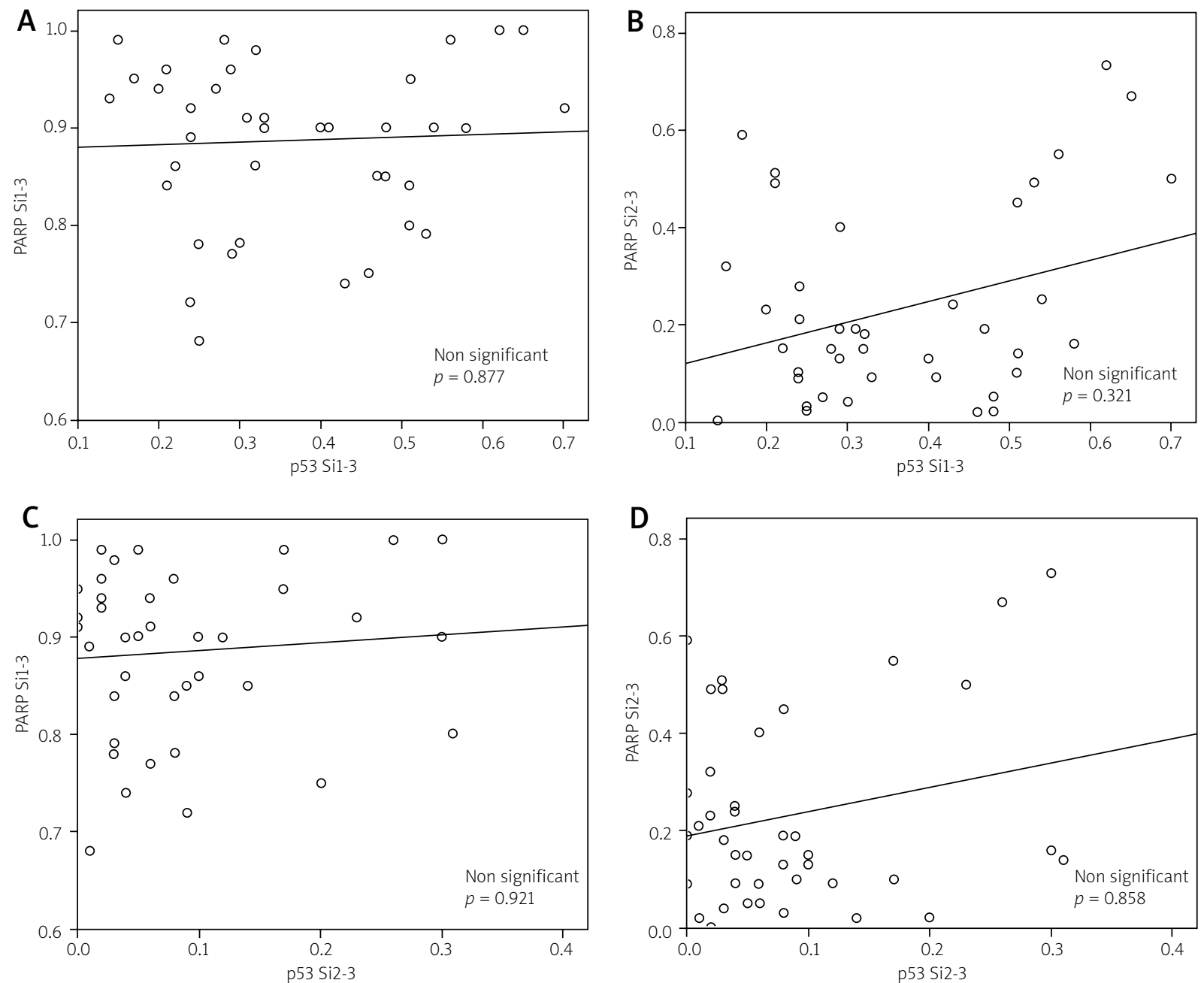

Fig. 4. Correlation between $p 53$ and PAPR1 staining intensity. There is a dot plot and linear correlation of the results of staining indices. The $p$ values are evaluated by Spearman's rank order correlation test. There are no significant correlations between the staining indices. (PARP1 - Poly(ADP-ribose) polymerase 1, staining index (Si) $1-3$ is the ratio of the immunopositive $(1+, 2+, 3+)$ cells; and the Si2-3 is the ratio of the intense positive $(2+, 3+)$ cells).

our data indicate that PARP1 and p53 immunohistochemistry represents useful and simple methods aiding the accurate diagnosis and grading of meningiomas.

\section{Acknowledgements}

The authors are thankful to Mrs Livia Beke for technical assistance.

This study was supported by the Hungarian Brain Research Program - Grants No. KTIA_13_NAP-A-11/7 and V-3 (to T.H. and A.K.).

\section{Disclosure}

Authors report no conflict of interest.

\section{References}

1. Abramovich CM, Prayson RA. Histopathologic features and MIB-1 labeling indices in recurrent and nonrecurrent meningiomas. Arch Pathol Lab Med 1999; 123: 793-800.

2. Adamczyk A, Jesko H, Strosznajder RP. Alzheimer's disease related peptides affected cholinergic receptor mediated poly(ADP-ribose) polymerase activity in the hippocampus. Folia Neuropathol 2005; 43: 139-142. 
3. Affar el B, Shah RG, Dallaire AK, Castonguay V, Shah GM. Role of poly(ADP-ribose) polymerase in rapid intracellular acidification induced by alkylating DNA damage. Proc Natl Acad Sci U S A 2002; 99: 245-250.

4. Amatya VJ, Takeshima Y, Sugiyama K, Kurisu K, Nishisaka T, Fukuhara T, Inai K. Immunohistochemical study of Ki-67 (MIB-1), p53 protein, p21WAF1, and p27KIP1 expression in benign, atypical, and anaplastic meningiomas. Hum Pathol 2001; 32: 970-975.

5. Bodi I, Hortobagyi T, Buk S. A 72-year-old woman with right frontal extra-axial mass. Brain Pathol 2008; 18: 279-282.

6. Brustmann H. Poly(adenosine diphosphate-ribose) polymerase expression in serous ovarian carcinoma: correlation with p53, MIB-1, and outcome. Int J Gynecol Pathol 2007; 26: 147-153.

7. Cho H, Ha SY, Park SH, Park K, Chae YS. Role of p53 gene mutation in tumor aggressiveness of intracranial meningiomas. J Korean Med Sci 1999; 14: 199-205.

8. Chozick BS, Benzil DL, Stopa EG, Pezzullo JC, Knuckey NW, Epstein $\mathrm{MH}$, Finkelstein SD, Finch PW. Immunohistochemical evaluation of erbB-2 and p53 protein expression in benign and atypical human meningiomas. J Neurooncol 1996; 27: 117-126.

9. De Vos M, Schreiber V, Dantzer F. The diverse roles and clinical relevance of PARPs in DNA damage repair: Current state of the art. Biochem Pharmacol 2012; 84: 137-146.

10. el-Deiry WS, Tokino T, Velculescu VE, Levy DB, Parsons R, Trent JM, Lin D, Mercer WE, Kinzler KW, Vogelstein B. WAF1, a potential mediator of p53 tumor suppression. Cell 1993; 75: 817-825.

11. Farmer H, McCabe N, Lord CJ, Tutt AN, Johnson DA, Richardson TB, Santarosa M, Dillon KJ, Hickson I, Knights C, Martin NM, Jackson SP, Smith GC, Ashworth A. Targeting the DNA repair defect in BRCA mutant cells as a therapeutic strategy. Nature 2005; 434: 917-921.

12. Galia A, Calogero AE, Condorelli R, Fraggetta F, La Corte A, Ridolfo F, Bosco P, Castiglione R, Salemi M. PARP-1 protein expression in glioblastoma multiforme. Eur J Histochem 2012; 56: e9.

13. Gehl Z, Bai P, Bodnár E, Emri G, Remenyik É, Németh J, Gergely P, Virág L, Szabó É. Poly(ADP-ribose) in the skin and in melanomas. Histol Histopathol 2012; 27: 651-659.

14. Godoy H, Mhawech-Fauceglia P, Beck A, Miller A, Lele S, Odunsi K. Expression of poly (adenosine diphosphate-ribose) polymerase and p53 in epithelial ovarian cancer and their role in prognosis and disease outcome. Int J Gynecol Pathol 2011; 30: 139-144.

15. Hollstein M, Sidransky D, Vogelstein B, Harris CC. p53 mutations in human cancers. Science 1991; 253: 49-53.

16. Hortobagyi T, Görlach C, Benyó Z, Lacza Z, Hortobágyi S, Wahl M, Harkany T. Inhibition of neuronal nitric oxide synthase-mediated activation of poly(ADP-ribose) polymerase in traumatic brain injury: neuroprotection by 3-aminobenzamide. Neuroscience 2003; 121: 983-990.

17. Hortobagyi T, Troakes C, Nishimura AL, Vance C, van Swieten JC, Seelaar H, King A, Al-Sarraj S, Rogelj B, Shaw CE. Optineurin inclusions occur in a minority of TDP-43 positive ALS and FTLDTDP cases and are rarely observed in other neurodegenerative disorders. Acta Neuropathol 2011; 121: 519-527.

18. Jaskolski D, Papierz T, Liberski PP, Sikorska B. Ultrastructure of meningiomas: autophagy is involved in the pathogenesis of “intranuclear vacuoles”. Folia Neuropathol 2012; 50: 187-193.
19. Kamei Y, Watanabe M, Nakayama T, Kanamaru K, Waga S, Shiraishi T. Prognostic significance of p53 and p21WAF1/CIP1 immunoreactivity and tumor micronecrosis for recurrence of meningiomas. J Neurooncol 2000; 46: 205-213.

20. Karamitopoulou E, Perentes E, Tolnay M, Probst A. Prognostic significance of MIB-1, p53, and bcl-2 immunoreactivity in meningiomas. Hum Pathol 1998; 29: 140-145.

21. Kase M, Vardja M, Lipping A, Asser T, Jaal J. Impact of PARP-1 and DNA-PK expression on survival in patients with glioblastoma multiforme. Radiother Oncol 2011; 101: 127-131.

22. Kastan MB, Kuerbitz SJ. Control of G1 arrest after DNA damage. Environ Health Perspect 1993; 101 Suppl 5: 55-58.

23. Kato Y, Nishihara H, Mohri H, Kanno H, Kobayashi H, Kimura T, Tanino M, Terasaka S, Tanaka S. Clinicopathological evaluation of cyclooxygenase-2 expression in meningioma: immunohistochemical analysis of 76 cases of low and high-grade meningioma. Brain Tumor Pathol 2014; 31: 23-30.

24. Klauschen F, von Winterfeld M, Stenzinger A, Sinn BV, Budczies J, Kamphues C, Bahra M, Wittschieber D, Weichert W, Striefler J, Riess H, Dietel M, Denkert C. High nuclear poly-(ADP-ribose)polymerase expression is prognostic of improved survival in pancreatic cancer. Histopathology 2012; 61: 409-416.

25. Koshland DE Jr. Molecule of the year. Science 1993; 262: 1953.

26. Kurosaki T, Ushiro H, Mitsuuchi Y, Suzuki S, Matsuda M, Matsuda Y, Katunuma N, Kangawa K, Matsuo H, Hirose T, Inayamall S, Shizuta Y. Primary structure of human poly(ADP-ribose) synthetase as deduced from cDNA sequence. J Biol Chem 1987; 262: 15990-15997.

27. Lacza Z, Horváth EM, Komjáti K, Hortobágyi T, Szabó C, Busija DW. PARP inhibition improves the effectiveness of neural stem cell transplantation in experimental brain trauma. Int J Mol Med 2003; 12: 153-159.

28. Lanzafame S, Torrisi A, Barbagallo G, Emmanuele C, Alberio N, Albanese V. Correlation between histological grade, MIB-1, p53, and recurrence in 69 completely resected primary intracranial meningiomas with a 6 year mean follow-up. Pathol Res Pract 2000; 196: 483-488.

29. Le Page F, Schreiber V, Dherin C, De Murcia G, Boiteux S. Poly(ADPribose) polymerase-1 (PARP-1) is required in murine cell lines for base excision repair of oxidative DNA damage in the absence of DNA polymerase beta. J Biol Chem 2003; 278: 18471-18477.

30. Lee MH, Na H, Kim EJ, Lee HW, Lee MO. Poly(ADP-ribosyl)ation of p53 induces gene-specific transcriptional repression of MTA1. Oncogene 2012; 31: 5099-5107.

31. Lewy-Trenda I, Omulecka A, Janczukowicz J, Papierz W. The morphological analysis of vasculature and angiogenic potential in meningiomas: immunoexpression of CD31 and VEGF antibodies. Folia Neuropathol 2003; 41: 149-153.

32. Longstreth WT Jr, Dennis LK, McGuire VM, Drangsholt MT, Koepsell TD. Epidemiology of intracranial meningioma. Cancer 1993; 72: 639-648.

33. Louis DN, Ohgaki H., Wiestler OD, Cavenee WK (eds.). WHO Classification of Tumours of the Central Nervous System. IARC, Lyon 2007.

34. Louis DN, Ohgaki H, Wiestler OD, Cavenee WK, Burger PC, Jouvet A, Scheithauer BW, Kleihues P. The 2007 WHO classifi- 
cation of tumours of the central nervous system. Acta Neuropathol 2007; 114: 97-109.

35. Makogon NV, Aleksieieva IM. Poly(ADP-ribose) polymerase (PARP): physiological and pathological roles. Fiziol Zh 2012; 58: 95-112.

36. Malanga M, Pleschke JM, Kleczkowska HE, Althaus FR. Poly(ADP-ribose) binds to specific domains of p53 and alters its DNA binding functions. J Biol Chem 1998; 273: 11839-11843.

37. Matsuno A, Nagashima T, Matsuura R, Tanaka H, Hirakawa M, Murakami M, Tamura A, Kirino T. Correlation between MIB-1 staining index and the immunoreactivity of $\mathrm{p} 53$ protein in recurrent and non-recurrent meningiomas. Am J Clin Pathol 1996; 106: 776-781.

38. Matyja E, Kroh H, Bojarski P. Intracranial meningiomas following irradiation therapy for brain tumors. Folia Neuropathol 1994; 32: 253-254.

39. Matyja E, Taraszewska A, Marszalek P. Necrosis and apoptosis of tumor cells in embolized meningiomas: histopathology and P53, BCL-2, CD-68 immunohistochemistry. Folia Neuropathol 1999; 37: 93-98.

40. Molloy-Simard V, St-Laurent JF, Vigneault F, Gaudreault M, Dargis N, Guérin MC, Leclerc S, Morcos M, Black D, Molgat Y, Bergeron D, de Launoit $Y$, Boudreau F, Desnoyers S, Guérin S. Altered expression of the poly(ADP-ribosyl)ation enzymes in uveal melanoma and regulation of PARG gene expression by the transcription factor ERM. Invest Ophthalmol Vis Sci 2012; 53: 6219-6231.

41. Nagashima G, Aoyagi M, Yamamoto M, Yamamoto S, Wakimoto H, Ohno K, Yamamoto K, Hirakawa K. P53 overexpression and proliferative potential in malignant meningiomas. Acta Neurochir (Wien) 1999; 141: 53-61.

42. Oei SL, Keil C, Ziegler M. Poly(ADP-ribosylation) and genomic stability. Biochem Cell Biol 2005; 83: 263-269.

43. Ohgaki H, Eibl RH, Schwab M, Reichel MB, Mariani L, Gehring M, Petersen I, Höll T, Wiestler OD, Kleihues P. Mutations of the p53 tumor suppressor gene in neoplasms of the human nervous system. Mol Carcinog 1993; 8: 74-80.

44. Ohkoudo M, Sawa H, Hara M, Saruta K, Aiso T, Ohki R, Yamamoto H, Maemura E, Shiina Y, Fujii M, Saito I. Expression of p53, MDM2 protein and Ki-67 antigen in recurrent meningiomas, J Neurooncol 1998; 38: 41-49.

45. Omulecka A, Papierz W, Nawrocka-Kunecka A, Lewy-Trenda I. Immunohistochemical expression of progesterone and estrogen receptors in meningiomas. Folia Neuropathol 2006; 44: 111-115.

46. Ozen O, Demirhan B, Altinors N. Correlation between histological grade and MIB-1 and p53 immunoreactivity in meningiomas. Clin Neuropathol 2005; 24: 219-224.

47. Perry A, Scheithauer BW, Stafford SL, Lohse CM, Wollan PC. "Malignancy" in meningiomas: a clinicopathologic study of 116 patients, with grading implications. Cancer 1999; 85: 2046-2056.

48. Perry A, Stafford SL, Scheithauer BW, Suman VJ, Lohse CM. The prognostic significance of MIB-1, p53, and DNA flow cytometry in completely resected primary meningiomas. Cancer 1998; 82: 2262-2269.
49. Prayson RA. Malignant meningioma: a clinicopathologic study of 23 patients including MIB1 and p53 immunohistochemistry. Am J Clin Pathol 1996; 105: 719-726.

50. Pykett MJ, Landers J, George DL. Expression patterns of the p53 tumor suppressor gene and the $\mathrm{mdm} 2$ proto-oncogene in human meningiomas. J Neurooncol 1997; 32: 39-44.

51. Rojo F, García-Parra J, Zazo S, Tusquets I, Ferrer-Lozano J, Menendez S, Eroles P, Chamizo C, Servitja S, Ramírez-Merino N, Lobo F, Bellosillo B, Corominas JM, Yelamos J, Serrano S, Lluch A, Rovira A, Albanell J. Nuclear PARP-1 protein overexpression is associated with poor overall survival in early breast cancer. Ann Oncol 2012; 23: 1156-1164.

52. Sabisz M, Wesierska-Gadek J, Skladanowski A. Increased cytotoxicity of an unusual DNA topoisomerase II inhibitor compound C-1305 toward HeLa cells with downregulated PARP-1 activity results from re-activation of the $\mathrm{p} 53$ pathway and modulation of mitotic checkpoints. Biochem Pharmacol 2010; 79: 1387-1397.

53. Schiewer MJ, Goodwin JF, Han S, Brenner JC, Augello MA, Dean JL, Liu F, Planck U, Ravindranathan P, Chinnaiyan AM, McCue P, Gomella LG, Raj GV, Dicker AP, Brody JR, Pascal JM, Centenera MM, Butler LM, Tilley WD, Feng FY, Knudsen KE. Dual roles of PARP-1 promote cancer growth and progression. Cancer Discov 2012; 2: 1134-1149

54. Songin M, Jeśko H, Czapski G, Adamczyk A, Strosznajder RP. GSK-3beta and oxidative stress in aged brain. Role of poly(ADP-ribose) polymerase-1. Folia Neuropathol 2007; 45: 220-229.

55. Strosznajder R, Gadamski R, Walski M. Inhibition of poly(ADPribose) polymerase activity protects hippocampal cells against morphological and ultrastructural alteration evoked by ischemia-reperfusion injury. Folia Neuropathol 2005; 43: 156-165.

56. Taraszewska A, Matyja E. Lectin binding pattern in meningiomas of various histological subtypes. Folia Neuropathol 2007; 45: 9-18.

57. Terzi A, Saglam EA, Barak A, Soylemezoglu F. The significance of immunohistochemical expression of Ki-67, p53, p21, and p16 in meningiomas tissue arrays. Pathol Res Pract 2008; 204: 305-314.

58. Wieler S, Gagné JP, Vaziri H, Poirier GG, Benchimol S. Poly(ADPribose) polymerase- 1 is a positive regulator of the $\mathrm{p} 53$-mediated $\mathrm{G} 1$ arrest response following ionizing radiation. J Biol Chem 2003; 278: 18914-18921.

59. Wiemels J, Wrensch M, Claus EB. Epidemiology and etiology of meningioma. J Neurooncol 2010; 99: 307-314.

60. Yu SW, Andrabi SA, Wang H, Kim NS, Poirier GG, Dawson TM, Dawson VL. Apoptosis-inducing factor mediates poly(ADP-ribose) (PAR) polymer-induced cell death. Proc Natl Acad Sci USA 2006; 103: 18314-18319.

61. Yu SW, Wang H, Poitras MF, Coombs C, Bowers WJ, Federoff HJ, Poirier GG, Dawson TM, Dawson VL. Mediation of poly(ADP-ribose) polymerase-1-dependent cell death by apoptosis-inducing factor. Science 2002; 297: 259-263.

62. Zhang O, Li Y, Li X, Zhou W, Shi B, Chen H, Yuan W. PARP-1 Val762Ala polymorphism, CagA+ H. pylori infection and risk for gastric cancer in Han Chinese population. Mol Biol Rep 2009; 36: 1461-1467. 